\title{
Continuous Rearing of the Red Palm Weevils, Rhynchophorus ferrugineus (Olivier), 1970 on Sugarcane in Laboratory for Biological Studies (Coleoptera: Dryophthoridae)
}

\author{
${ }^{1}$ Norzainih, J. J., ${ }^{1}$ Harris M.N., ${ }^{1}$ Nurul Wahida, O.*, ${ }^{1}$ Salmah, Y. and ${ }^{2}$ Norefrina Shafinaz, M., N.
}

\begin{abstract}
Red Palm Weevil (RPW), Rhynchophorus ferrugineus (Coleoptera: Dryophthoridae) is a very destructive insect pest to plants under the family of Palmacea such as dates palm, coconut tree, sago palm as well as oil palm. Many studies conducted on RPW required large numbers of weevils of various stages, hence rearing is needed to solve the problem. In this study, RPW reared on sugarcane in the laboratory for several generations to facilitate biological studies of this tissue-boring pest. The rearing was conducted at National University of Malaysia, Bangi, Selangor. Adult weevils collected from the field by using pheromone trapping method. The adult weevils supplied with stems of sugarcane for food and they were also oviposited on it. The larvae were fed on stems of sugarcane until pupation. The length and size of the sugarcane stems were propotional to the size of the larva. Data on the duration of developmental life stages were recorded. The larvae fully developed on sugarcane and molted 8 times within the mean of 70 days. The larvae were able to construct cocoons due to the availability of fibers in the sugarcane. Sugarcane is the best diet to be used in the mass laboratory rearing of RPW in Malaysia.
\end{abstract}

Keywords - Laboratory, rearing, Red Palm Weevil, sugarcane.

\section{INTRODUCTION}

$\mathbf{R}_{a}^{\mathrm{B}}$ ED Palm Weevil (RPW), Rhynchophorus ferrugineus, is a serious pests of palms throughout South and Southeast Asia which are the native habitat of this pest [1]. The invasion of $R$. ferrugineus are rapidly spreading to the Middle East, Europe, USA and South America [2]-[3]-[4]-[5]. This pest feeds primarily on Arecaceae such as dates palms, coconut tree, sago palm as well as oil palm. Besides, it has also been recorded on Agavaceae (century plant), and Poaceae (sugar cane) [6].

${ }^{1}$ Nurul Wahida Othman is with the National University of Malaysia, Faculty of Science and Technology, School of Enviromental Sciences and Natural Resources, Centre of Insect Systematics, 43600 Bangi, Selangor, Malaysia

${ }^{2}$ Norefrina Shafinaz Md Nor is with the National University of Malaysia, Faculty of Science and Technology, School of Biosciences and Biotechnology, 43600 Bangi, Selangor, Malaysia
Present study reported that Red Palm Weevil had caused severe damaged of coconut palm in South East Malaysia particularly in Kelantan and Terengganu [7]-[8]-[9]. Record shows that RPW probably have the capability to host shift and infest oil palm [10]. In Malaysia, coconut palm is not regarded as a commercial crop as compared to oil palm industry which contributes RM62.5 billion to the nation's economy [11]. It is strongly possible that red palm weevil can become a serious threat to oil palm industry few years from now if nothing done to prevent it further invasion.

There are so many studies conducted regarding the insect in order to collect information on this economically important pest of palm in many parts of the world. However, only few studies have been conducted on the physiological aspect of RPW especially in Malaysia. There are several methods developed for mass rearing of RPW in Middle East countries. However, there are lack of methods have been optimized on continuous mass rearing of RPW in Malaysia. Rearing ensure enough supply of samples for study which usually required large numbers of weevils of various stages. This rearing study is another effort to collect information on the life cycle of this pest weevils under laboratory in Malaysia as well as to provide enough samples of various life stages for further physiological study.

\section{MATERIALS AND METHOD}

\section{A. Sampling}

Samples of male and female adults of RPW were collected from the infesting palm trees in several selected areas in Kuala Terengganu with the help of Department of Agriculture in those areas. Samples were adult weevils of RPW that provide the initial samples for rearing.

\section{B. Laboratory Rearing}

RPW were reared to provide samples for the research which required large numbers of RPW of various stages. The rearing process was carried out in a rearing room with the mean of $30 \pm 2^{\circ} \mathrm{C}$ and $60-80 \% \mathrm{RH}$. The photoperiod was approximately 12:12 L:D. The room was also used for handling and preparing food for the samples as well as 
storage room for stems of sugarcane. Equipment and materials required for rearing on sugarcane are as follow: machete, medium-sized and large rectangular plastic container, glass petri dish, forceps, test tube racks, water spray bottle, filter papers and digimatic calliper.

Adult weevils: Sample of adult weevils collected from the field were cleaned and kept in medium-sized plastic container as groups of paired males and females. They were provided with slices of sugarcane stems for feeding and egg laying. Containers were put side by side on steel racks to facilitate monitoring (Fig. 1). Female weevils use the sugarcane slices as their oviposition sites and lay their eggs onto it. The lids of the containers were closed with netting fabric from the inside to avoid flies infestation on the sugarcane.

Eggs: Sugarcane holding the eggs were removed from the container of adult weevils and for replacement new sugarcane slices were placed into the container. Eggs found in the sugarcane slices were transferred and placed on wet filter papers inside a petri dish (Fig. 2). The filter papers were wet with water as needed to avoid the eggs from drying. The eggs were daily monitored to avoid the newly hatched larvae dying from starving. After two to five days, newly hatched larvae were transferred to small pieces of sugarcane stems.

Larvae: Newly hatched larvae from the filter papers and inside the sugarcane stems were transferred to new pieces of sugarcane stems. To facilitate the monitoring of molting of the small larva, small pieces of sugarcane were used. The pieces of sugarcane stem were arranged on test tube rack (Fig. 3). As the entrance for the larva, a small hole was made at the end of each piece of the sugarcane stems. The larva was put into the hole to initiate boring. One week after feeding, larger larvae were transferred to other container with larger and longer fresh pieces of sugarcane stems, this was based on the size of larvae at different developmental stages (Fig. 4). The larger the larva, the larger (diameter) and longer the sugarcane stem used. The larvae head capsule width and length were measured weekly to monitor the molting of the larvae (Fig. 5). Head measurements of small early instar larva were taken under the stereoscopic microscope. Last instar larva made cocoon from the fibers inside the sugarcane stem.

Pupae: Red Palm Weevils construct cocoon for their pupation (Fig. 7). The cocoons were made from the fibers of sugarcane. The pieces of sugarcane stem were split open after about a week of feeding of the last instar larvae, and cocoons were collected (Fig. 6). Cocoons were placed in a plastic container, sprayed with water as needed, and closed with lid. Two weeks after collecting the cocoons they were checked daily for adult emergence (Fig. 8). Adults were collected by hand and placed in plastic containers.

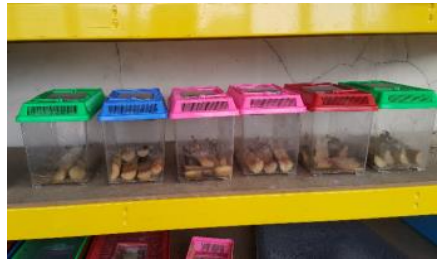

Fig. 1: Rearing boxes for adult weevils

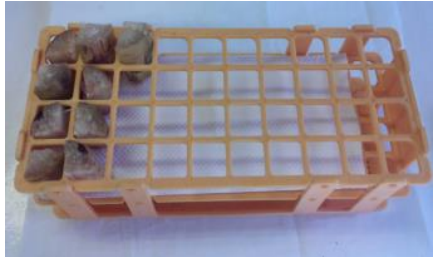

Fig. 3: Pieces of sugarcane stem containing newly hatched larva.

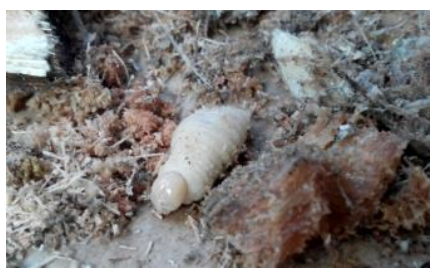

Fig. 5: Newly molted larva of RPW.

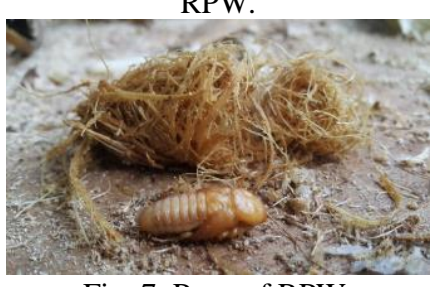

Fig. 7: Pupa of RPW.

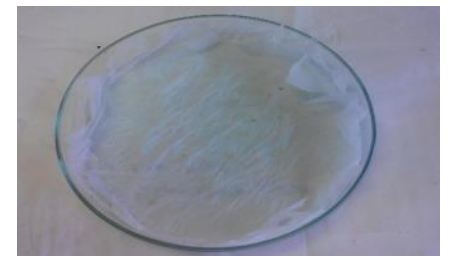

Fig. 2: Petri dish contains eggs on the moistened filter paper.

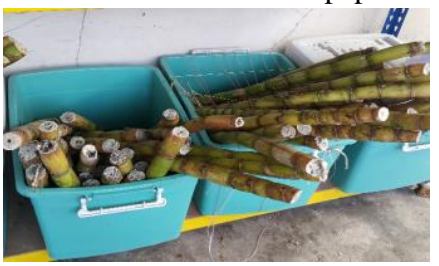

Fig. 4: Rearing boxes for the developing larva.

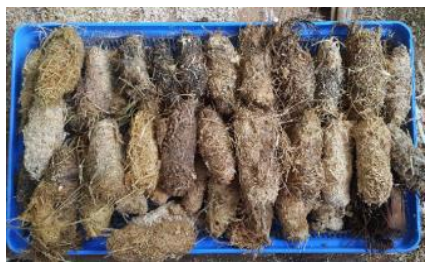

Fig. 6: Cocoons collected from the sugarcane stems.

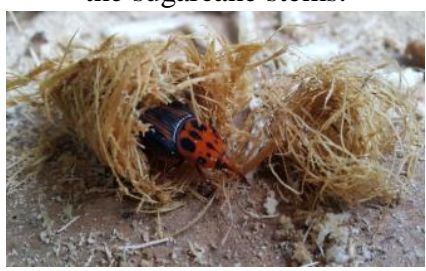

Fig. 8: Newly emerged adult of RPW.

\section{C.Larval Stage Identification}

In order to identify the larval instar stages, the head capsule measurement of larva (length and width) was taken weekly by using digimatic calliper. The identification of larval stages was done by using Dyar's ratio. Dyar's Law stated that during development of an immature insect, increases in body size occur in discrete step, with highly sclerotized body parts exhibiting predictable and regular increases by a relatively constant factor [12].

\section{RESUlT AND DISCUSSIONS}

Red Palm Weevil was successfully reared in the laboratory on sugarcane which is one of the natural food of the pest weevils. Reference [12] stated that sugarcane is the best medium for the development of all larval stages to pupa in lab conditions. The availability of sugarcane in Malaysia also contribute to the possibility of it to be used in the rearing process. Besides, sugarcanes also are more rot resistance, hence able to provide good quality of food for much longer period compared to the young shoots of palms. In addition, sugarcane was naturally contained with fiber which needed for RPW to make their cocoon. The presence of natural fiber 
in the sugarcane ensure adequate and timely accurate supply of fiber in the final stage of RPW instar.

TABLE I

HEAD MEASUREMENTS OF RPW DURING LARVAL STAGE

\begin{tabular}{|c|c|c|c|c|}
\hline \multirow{2}{*}{$\begin{array}{l}\text { Larva } \\
\text { Instar }\end{array}$} & \multicolumn{2}{|c|}{ Head Length (mm) } & \multicolumn{2}{|c|}{ Head Width (mm) } \\
\hline & Mean & Range & Mean & Range \\
\hline 1 & $0.92 \pm 0.03$ & $0.76-1.08$ & $0.70 \pm 0.01$ & $0.65-0.80$ \\
\hline 2 & $1.37 \pm 0.07$ & $1.08-1.68$ & $1.01 \pm 0.04$ & $0.80-1.20$ \\
\hline 3 & $2.05 \pm 0.12$ & $1.68-2.58$ & $1.54 \pm 0.08$ & $1.20-1.89$ \\
\hline 4 & $3.16 \pm 0.11$ & $2.58-3.78$ & $2.16 \pm 0.08$ & $1.89-2.58$ \\
\hline 5 & $4.69 \pm 0.09$ & $3.78-5.14$ & $3.31 \pm 0.06$ & $2.58-3.57$ \\
\hline 6 & $6.04 \pm 0.22$ & $5.14-7.27$ & $4.32 \pm 0.18$ & $3.57-5.20$ \\
\hline 7 & $8.59 \pm 0.20$ & $7.27-9.42$ & $5.93 \pm 0.16$ & $5.20-6.65$ \\
\hline 8 & $10.32 \pm 0.20$ & $9.42-11.50$ & $7.50 \pm 0.20$ & $6.65-8.74$ \\
\hline
\end{tabular}

Table 1 showed the head measurement of the larva during the development process. Reference [14] categorized larvae into 3 stages based on head capsule width which are young $(<2.8 \mathrm{~mm})$, medium $(2.8-6.0 \mathrm{~mm})$ and mature $(>6.0 \mathrm{~mm})$. In order to implement effective control with optimal time to intervene with insecticides and entomopathogenic nematodes, the knowledge on the life history such as the development of RPW is very important [14]. The data on the larval stage can be used to study the physiology and biochemistry of the pest during their development.

The total development period of RPW from egg to adult is about three months. The larva molt 8 times during its larvae stage. Result revealed is in line with the works of [15]-[16]. In contrast, [17] recorded that the life cycle of RPW takes about four months to complete. Meanwhile, [2] recorded that larva of RPW feed from 25 to 105 days and molt 9 to 20 times during its larvae stage. Reference [18] stated that RPW fed on artificial diet reached up to 15 stages. Different climate, food materials and other life parameter between countries may cause the life cycle of RPW to slightly change.

Based on the result obtained, the egg takes about 2-5 days to hatch while the larva takes about 70-80 days before molted to pupa. The pupal stage takes a range of two to three weeks for the emergence of the adult weevils. This result agree with that estimated by [18]-[19]-[20]. The first and fourth instar were the shortest stages of larval development in which both takes only around 7 days before molted to the next instar. The longest stage was taken by the second instar which is around 14 days to complete. The other instar stages take about 8-10 days to complete. It can be concluded that sugarcane is the best natural food material for continuous mass laboratory rearing of RPW in Malaysia.

\section{ACKNOWLEDGMENT}

The authors would like to thank Dr. Wahizatul Afzan Azmi from Universiti Malaysia Terengganu and Department of Agriculture in Kuala Terengganu for the generous help in surveying the area and sampling as well as the knowledge transfer given. This research was funded by the grant 02-01-
01-SF1135 from the Ministry of Sciences, Technology and Inovation (MOSTI) and GUP-2014-086 from Research University Grant, Universiti Kebangsaan Malaysia, 43600 Bangi, Selangor, Malaysia.

\section{REFERENCES}

[1] S. Sadakathulla, "Management of Red Palm Weevil, Rhynchophorus ferrugineus," The Planter, vol. 67, issue 786, pp. 415-419, 1991.

[2] A. Wattanapongsiri, "A revision of the genera Rhynchophorus and Dynamis (Coleoptera: Curculionidae)," Department of Agriculture Science Bulletin, vol 1, pp. 328, 1966.

[3] D. Hernández-Marante, F. Folk, A. Sánchez, R. Fernández-Escobar "Control of red palm weevil, Rhynchophorus ferrugineus Olivier, using trunk injections and foliar sprays," Health Vegetable-Pest Bulletin, vol 29,pp. 563-573, 2003.

[4] G. L. Zhang, W. D. Fu and K. Liu. Agricultural Invasive Pests in China. Beijing: Science Press, 2008, pp. 172.

[5] P. F. Rugman-Jones, C. D. Hoddle, M. S. Hoddle and R. Stouthamer, "The lesser of two weevils: molecular-genetics of pest palm weevil populations confirm Rhynchophorus vulneratus (Panzer 1798) as a valid species distinct from $R$. ferrugineus (Olivier 1790), and reveal the global extent of both," PLoS ONE, vol 8, issue 10, Oct 2013. http://dx.doi.org/10.1371/journal.pone.0078379

[6] C. Malumphy and H. Moran, "Red Palm Weevil, Rhynchophorus ferrugineus, Plant Pest Fact Sheet. The Food and Environment Research Agency (FERA), 2009.

[7] N. Basari, W. A. Azmi, Z. Chik and A. R. Abdul Razak, Coconut Pest Alert! Onslought of Coconut Palms by the Lethat Pest Red Palm Weevil, Rhynchophorus ferrugineus, in Terengganu. INFOKUS, Universiti Malaysia Terengganu, vol. 35, June 2011.

[8] A. A. Wahizatul, C. Zazali, A. R. Abdul Rahman and A. G. Nurul Izzah, "A new invasive coconut pest in Malaysia: the red palm weevil (Curculionidae: Rhynchophorus ferrugineus)," The Planter, vol 89, issue 1043, pp. 97-110, 2013.

[9] C. Zazali. Department of Agriculture, Quarantine and Crop Protection Section, Terengganu, Malaysia, private communication, 2014.

[10] A. G. Idris, H. Mokhtaruddin, C. Zazali, O. Nurul Wahida, S. Yaakop and I. R. Hazmi, "The potential of red palm weevil infesting and destroying oil palm industry in Malaysia," The Planter, vol. 90, issue 1058, pp. 329-335, 2014.

[11] Bernama. Oil Palm to Contribute RM178b to Malaysia's Economy in 2020. News Straits Times, from http://www.nst.com.my/nst/articles/OilpalmtocontributeRM178btoMalaysi a_seconomyin2020/Article/, oct 2011.

[12] V. H. Resh and R. T. Carde. Encyclopedia of Insects. Academic Press, 2009.

[13] F. Shahina, M. Gulsher, S. Javed, T.A., "Khanum and M. I. Bhatti. Susceptibility of different life stages of red palm weevil, Rhynchophorus ferrugineus, to entomopathogenic nematodes," International Journal of Nematology, vol. 19, issue 2, pp.232-240, 2009.

[14] F. Abe, K. Hata and K. Sone, "Life history of the Red Plam Weevil, Rhynchophorus ferrugineus (Coleoptera: Dryophthoridae), in Southern Japan," Florida Entomologist, vol 92, issue 3, pp.421-425, sept. 2009. http://dx.doi.org/10.1653/024.092.0302

[15] S. T. Prabhu and R. S. Patil, "Studies on the biological aspects of red palm weevil Rhynchophorus ferrugineus (Oliv.)," Karnataka Journal of Agricultural Science, vol. 22, issue 2, pp. 732-733, 2009.

[16] H. F. Goonewaedena and M. S. Velu, "The red palm weevil, Rhynchophorus ferrugineus Olivier," Ceylon Coconut Quarterly, vol. 9, pp. 20-40, 1958.

[17] A. M. Ajlan, "Red Palm Weevil, Rhynchophorus ferrugineus, (Olivier) (Coleoptera: Curculionidae)," King Faisal University, Hofuf, Al-Hasa, Saudi Arabia, pp. 3127-3130, 2008.

[18] W. Kaakeh, A. A. Khamis, and M. M. Aboul-Nour, The Red Palm Weevil: The Most Dangerous Agricultural Pest. UAE University Printing Press, 2001, pp. 165.

[19] A. Sharaby and Z. M. Al-Dhafar, "Successful laboratory culture for the Red Palm Weevil, Rhynchophorus ferrugineus (Coleoptera: Curculionidae) reared on semi-artificial diet," Journal of Basic and Applied Scientific Research, vol. 3, pp. 1-7, 2013.

[20] F. El-Ezaby, "A biological in vitro study on the red Indian date palm weevil," Arab Journal of Plant Protection, vol. 15, pp. 84-87, 1997. 